\title{
Clarke \& Wright's Savings Algorithm and Genetic Algorithms Based Hybrid Approach for Flying Sidekick Traveling Salesman Problem
}

\author{
Büşra Özoğlu ${ }^{*}$, Emre Çakmak ${ }^{2}$, Tuğçe Koç3 \\ ${ }^{1}$ Piri Reis University, Faculty of Engineering, Department of Industrial Engneering, Istanbul, Turkey (ORCID: 0000-0003-4302-0813) \\ ${ }^{2}$ Piri Reis University, Faculty of Engineering, Department of Industrial Engneering, Istanbul, Turkey (ORCID: 0000-0002-3406-3144) \\ ${ }^{3}$ Piri Reis University, Faculty of Engineering, Department of Industrial Engneering, Istanbul, Turkey (ORCID: 0000-0002-0366-1029)
}

(This publication has been presented orally at HORA 2019 congress.)

(First received 1 August 2019 and in final form 24 October 2019)

(DOI: 10.31590 /ejosat.637816)

ATIF/REFERENCE: Özoğlu, B., Çakmak, E. \& Koç, T. (2019). Clarke \& Wright's Savings Algorithm and Genetic Algorithms Based Hybrid Approach for Flying Sidekick Traveling Salesman Problem. European Journal of Science and Technology, (Special Issue), 185192.

\begin{abstract}
Over the past few years, drones also known as unmanned aerial vehicles (UAV), have been adopted as a part of transportation activities in logistic sector. This paper investigates a new version of traveling salesman problem called as flying sidekick traveling salesman problem(FSTSP) in which trucks and drones serve the customers in coordination with the objective of minimizing the total delivery distance of trucks at the depot after completing the deliveries. Clarke \& Wright's savings algorithm is a well-known heuristics approach in literature, which gives better solution for classical vehicle routing problem. In this paper, a hybrid approach based on Clarke \& Wright's savings algorithm and genetic algorithm is proposed for solving the new version of travelling salesman problem. In the proposed hybrid algorithm, which is the sequential use of genetic algorithm and Clarke \& Wright's savings algorithm, is used for assignment of the truck, drone or both of them to serve the customer. The solution of the genetic algorithm, which is the well-known metaheuristic approach, is enhanced with Clarke \& Wright's savings algorithm. The aim of the problem is to minimize the total delivery distance according to the assignment decisions. This is the first hybrid approach in the literature including Clarke \& Wright's savings algorithm and genetic algorithm that applies for FSTSP problem. The hypothetical experiments conducted on various instances and results confirm the efficiency of the approach and give some insights on this drone delivery system.
\end{abstract}

Keywords: Flying sidekick traveling salesman problem, genetic algorithm, Clarke \& Wright's savings algorithm, drone

\section{Clarke \& Wright Tasarruf Algoritması ve Genetik Algoritmaya Dayalı Uçan Yardımcılı Gezgin Satıcı Problemi}

$\ddot{O} z$

Son yıllarda, insansız hava aracı olarak da bilinen drone'lar lojistik sektöründeki ulaştırma faaliyetlerinin bir parçası olarak kabul edilmiştir. Bu çalışmada gezgin satıcı probleminin yeni bir versiyonu olan uçan yardımcılı gezgin satıcı problemine bir çözüm önerisi geliştirilmiştir. Çalışmanın amacı kamyon ve drone'ların koordineli bir şekilde kullanımı ile teslimat yaparak, teslimatlar tamamlanana kadar kamyon tarafından kat edilen toplam teslimat mesafesinin minimize edilmesidir. Clarke \& Wright tasarruf algoritması literatürde sıklıkla kullanılan, klasik araç rotalama problemlerinde iyi sonuç veren sezgisel algoritmalardandır. Önerilen yaklaşım ile genetik algoritma ve Clarke \& Wright tasarruf algoritmasının sıralı kullanımı ile drone, kamyon ya da her ikisinin eş zamanlı olarak müşterilere atanması amaçlanmaktadır. Clarke \& Wright tasarruf algoritması sonuçları, iyi bilinen meta sezgisel algoritmalardan olan genetik algoritma ile iyileştirilmiştir. Bu problemin amacı atama kararlarına göre teslimat mesafesini en aza indirmektir. Bu çalışma Clarke \& Wright tasarruf algoritması ve genetik algoritmanın uçan yardımcılı gezgin satıcı problemine uygulandığı ilk çalışmadır. Çeşitli örnek problem setleri üzerine yapılan hipotetik analizler yaklaşımın etkinliğini onaylamakta ve drone teslimat sistemine bir bakış açısı geliştirmektedir.

\footnotetext{
* Corresponding Author: Piri Reis University, Faculty of Engineering, Department of Industrial Engneering, Istanbul, Turkey (ORCID: 0000-00034302-0813), bozoglu@pirireis.edu.tr
} 
Avrupa Bilim ve Teknoloji Dergisi

Anahtar Kelimeler: Uçan yardımcılı gezgin satıcı problemi, genetik algoritma, Clarke \& Wright tasarruf algoritması, drone

\section{Introduction}

The technology for unmanned aerial vehicles (UAVs) which is also known as drone has increased significantly in the past few years, and the list of potential uses for automated drones is growing in various disciplines especially it has gained a growing interests in the transportation activities because of the traffic congestion, the growing of the urban population and some restrictions in the land area. Delivery by drones is being promoted and researched by a growing number of firms, including Amazon, UPS, Google DHL and Walmart, as a possible alternative or complement to traditional delivery by trucks(Campbell, Sweeney, \& Zhang, 2017).

There are various investigations in the literature that applies flying sidekick travelling salesman problem(FSTSP). At the same time there are so many studies in the litarature which is called as a travelling salesman problem with drone(TSP-D) that has the same purpose with the FSTSP. FSTSP is firslty introduced by the Murray and Chu (2015). They provided two mathematical programming models aimed at optimal routing and scheduling of unmanned aircraft, and delivery trucks and they presented mixed integer linear programming formulations for two delivery-by-drone problems, along with heuristic solution approaches to solve problems of practical size. Huachi and Penna (2018) proposed two stage hybrid approach for FSTSP. They created the initial solution with the Concorde solver and an implementation of the Randomized Variable Neighborhood Descent (RVND) heuristic is used as a local search to obtain the problem solution for FSTSP.

Ferrandez et al. (2016) made a research to investigate the effectiveness of implementing unmanned aerial delivery vehicles in delivery networks to find the minimum cost. They developed mathematical formulations for closed form estimations for the optimal number of launch locations and the optimal total time of delivery. The design of the algorithm herein computes the minimal time of delivery utilizing k-means clustering to find launch locations, as well as a genetic algorithm to solve the truck route as a traveling salesmen problem. Campbell et al. (2017) provided a strategic analysis for the design of hybrid truck-drone delivery systems using continuous approximation modeling techniques to derive general insights. They formulated and optimized models of hybrid truck-drone delivery, where truck-based drones make deliveries simultaneously with trucks. Pugliese and Guerriero (2017) used a set of trucks equipped with a given number of drones, which aims to analyze the delivery process with drones, by taking into account the total transportation cost and highlighting strategical issues, related to the use of drones. Bouman and Schmidt (2018) modeled TSP-D problem as an integer program and develop several fast route-first, cluster- second heuristics based on local search and dynamic programming. Kim and Moon (2018) proposed a truck-drone system to overcome the flight-range limitation. They defined a drone station as the facility where drones and charging devices are stored.

Boysen et al. (2018) scheduled the delivery to customers by drones for given truck routes. They introduced efficient mixed-integer programs to minimize the total duraton of the delivery tour. Yoon (2018) constructed a model with mixed integer linear programming (MILP) optimization and assessed with a sensitivity analysis of several key parameters for TSP-D with multiple drones. Ha et al. (2018) considered TSP-D in which the objective is to minimize operational costs including total transportation cost and one created by waste time a vehicle has to wait for the other. The formulated the problem mathematically and two algorithms including from TSP with local search (TSP-LS) and Greedy Randomized Adaptive Search Procedure (GRASP), is based on a new split procedure that optimally splits any TSP tour into a TSP-D solution, which sequentially improved through local search operators are used at the solution stage. Saleu et al. (2018) proposed a heuristic solution of the parallel drone scheduling traveling salesman problem, which aims to minimize completion time. They proposed an iterative two-step heuristic, composed of: a coding step that transforms a solution into a customer sequence, and a decoding step that decomposes the customer sequence into a tour for the vehicle and trips for the drones. Yurek and Ozmutlu (2018) presented an iterative algorithm that is based on a decomposition approach to minimize delivery completion time for TSP-D. In the first stage, the truck route and the customers assigned to the drone are determined. In the second stage, a mixed- integer linear programming model is solved to optimize the drone route by fixing the routing and the assignment decisions that are made in the first stage.

Bouman et al. (2018) presented exact solution approaches for the TSP-D based on dynamic programming and provides an experimental comparison of these approaches. Agatz et al. (2018) proposed an innovative last-mile delivery concept in which a truck collaborates with a drone to make deliveries gives rise to TSP-D. Jeong et al. (2019) considered the effect of parcel weight on drone energy consumption and restricted flying areas for TSP-D. They developed a mathematical model that incorporates these issues and proposed a two-phase constructive and search heuristic algorithm to provide computational efficiency of the real-world cases problems. Kitjacharoenchai et al. (2019) presented a mixed integer programming (MIP) formulation TSP-D with the objective of minimizing the arrival time of both trucks and drones at the depot after completing the deliveries. A new algorithm based on insertion heuristics is developed to solve large sized problems.

The rest of this paper is organized as follows. In section 2, we provide material and method that was used in the problem solving stage. In section 3, results and discussion are provided in detail and section 3 gives conclusion and propose some recommendations.

\section{Material and Method}

In this paper, a hybrid approach based on Clarke \& Wright's savings algorithm and genetic algorithm is proposed for solving the flying sidekick travelling salesman problem. Genetic algorithm is used for assignment of the truck or drone and Clarke \& Wright's 
savings algorithm is used to determine the sequence of the customers. A new heuristic algorithm, which aims to find the distances, is used to connect the drones with truck.

\subsection{Flying Sidekick Traveling Salesman Problem}

Travelling salesman problem (TSP) is a combinatorial optimization problem which aims to find the shortest possible path given a set of cities and distances between every pair of them during the delivery process once and returns to the depot. Traditional last mile delivery by truck faces several problems in TSP. Because of the human driver and the large fraction of unproductive work, truck deliveries are costly and, furthermore, seen as a major source of negative effects on congestion, safety, and environment in large city centres(Boysen et al., 2018).

The FSTSP has emerged as an extension of TSP to oversome these deficiencies. The differences between FSTSP and TSP is illustrated in Figure 1. The FSTSP consists of delivering parcels using a truck and a UAV (drone), where some customers are attended by the truck and others by the UAV or assigning both of them at the same customer. Both the truck and UAV leave the depot in tandem. During the trip, the UAV can be launched at a customer node to delivery a parcel and then recovered at another node (Huachi \& Penna, 2018). Although drones can provide distinct advantages such as mobility, flexibility, and low cost, they have a fundamental drawback with their limitations in flight duration and flight restriction, making it difficult to use them in a large area operation. One way to overcome this barrier is the use of a hybrid delivery system consisting of a large ground vehicle and a small aerial vehicle (Jeong et al., 2019)

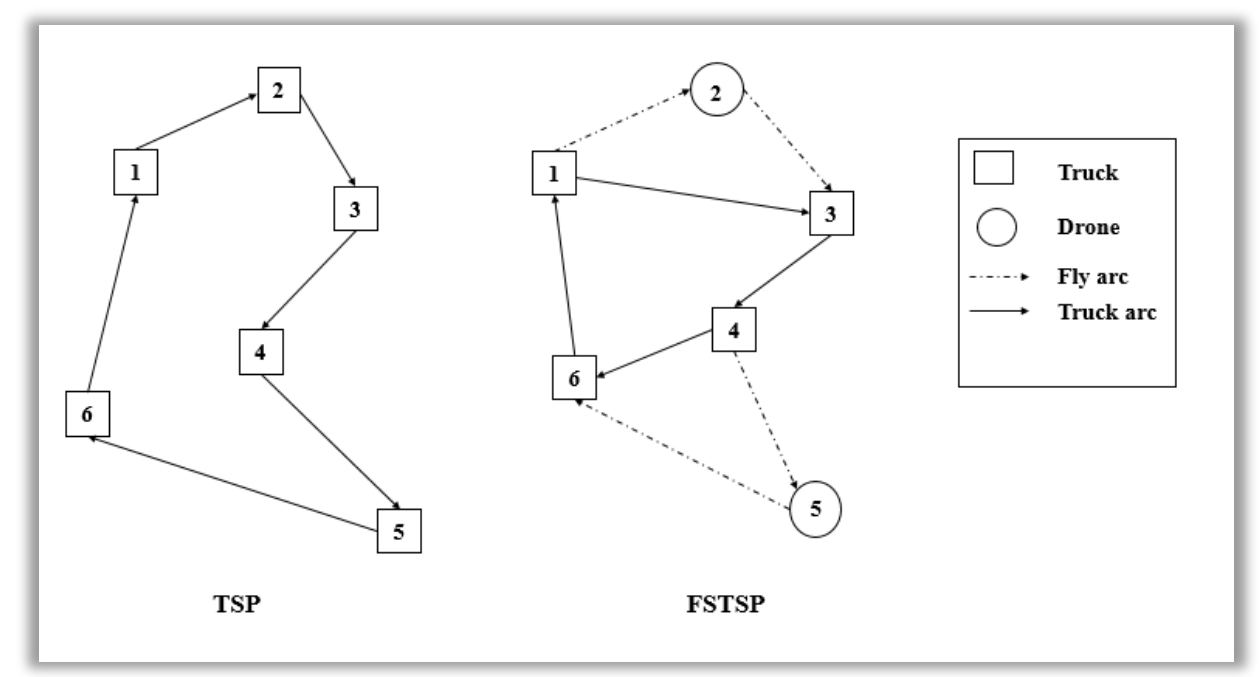

Figure 1: Delivery of Customers with TSP and FSTSP

\subsection{Problem Descriptions}

In this study, genetic algorithm and Clarke \& Wright's savings algorithm based hybrid approach is proposed to find the minimum distances for flying sidekick traveling salesman problem. Genetic algorithm is used for assignment of the truck and drone for the customers. Then, Clarke \& Wright's savings algorithm is used to sequence the customers. This process continues until the number of iteration is reached. According to assignment decisions and sequence of customers, a new heuristic algorithm is developed to find the minimum distances between two customer nodes including truck and drone. According to calculation, the drone is connected with truck where they are close to each other because truck wait drones until the drone satisfied the customer and turn back to the same node to charge its battery. The proposed hybrid algorithm flow chart is described detailed in Figure 2.

\subsubsection{Mathematical Model}

The mathematical model is determined to find the minimum total delivery distances. Visual basic software is used to encode the problem.

\section{- Mathematical Model Assumptions}

1. Although the UAV may visit only one customer per delivery, the truck may visit multiple customers while the UAV is in flight

2. The UAV is assumed to remain in constant flight while on a delivery, except to deliver the parcel at a customer

3. If the UAV is collected by the truck at some customer node $i$, the UAV may be re-launched from $i$

4. if the UAV is launched from $i$, it must return to the truck at node $i$

5. Neither the UAV nor the truck may visit any non-customer nodes (other than the depot, of course) and neither vehicle may revisit any customers (Murray \& Chu, 2015) 


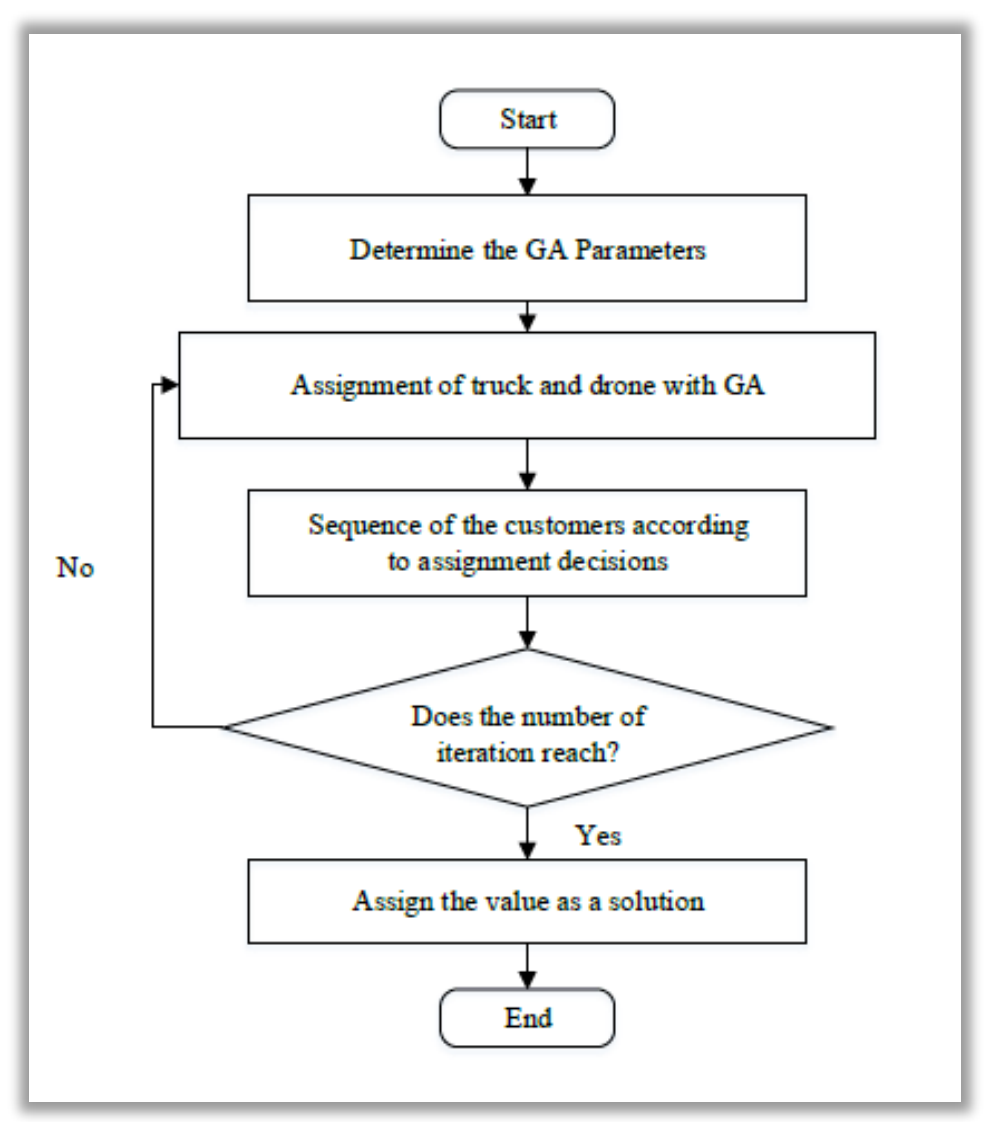

Figure 2: Flowchart of the Proposed Hybrid Algorithm

\section{- Pseudocode of the Proposed Mathematical Model}

Procedure GA\&Saving algorithm for FSTSP

Initialize: GA parameters, set the first transportation type assignment randomly to each gene repeat

for all (population) do

Call the genetic function.

Call the saving (Clark \& Wright Saving Algorithm) for subtour.

until (termination condition is met)

\subsection{Genetic Algorithms}

Genetic algorithm (GA) is an optimization method that uses a stochastic approach to randomly search for good solutions to a specified problem. These stochastic approaches use various analogies of natural systems to build promising solutions (Razali \& Geraghty, 2014) The basic steps of the GA summarised in Figure 3 (Baker \& Ayechew, 2003). GA evolves a population of candidate solutions that represented by a chromosome that is usually coded as a binary string. The fitness of each chromosome is then evaluated using a fitness function after the chromosome has been decoded. Upon the evaluation, a biased roulette wheel is used to randomly select pairs of chromosomes to undergo genetic operations like crossover, selection and mutation that natural phenomena observed in nature. This evolution process continues until the stopping criteria are reached.(Fan, Liang, \& Zahara, 2006) 


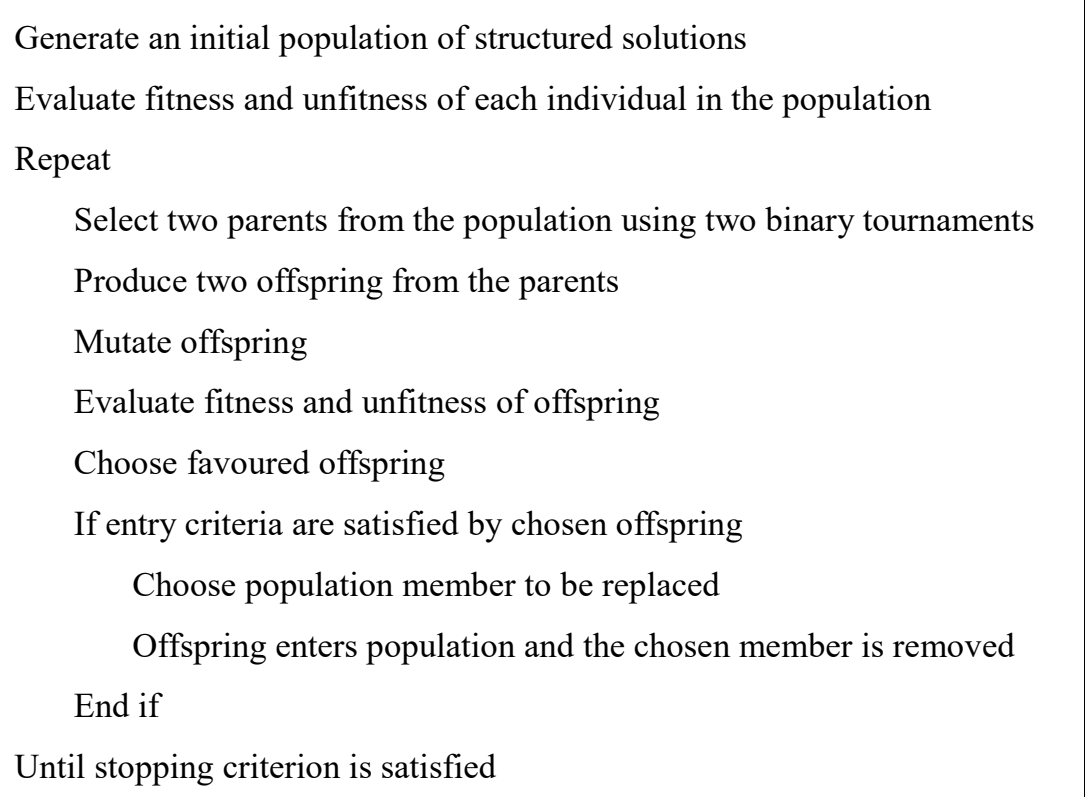

Figure 3: Basic Steps of the Genetic Algorithm

\subsection{Clarke \& Wright's Savings Algorithm}

The savings algorithm (CW), is firstly proposed by Clarke and Wright (1964) which is the most widely known heuristic algorithm for travelling salesman problem or classical vehicle routing problem. The concept of this algorithm is to determine the routes by the savings list in which values are sorted from largest to smallest (Pichpibul \& Kawtummachai, 2012).

In the classical version of the Clarke $\&$ Wright's Savings Algorithm, the distance matrix $d_{i j}$ is firstly described as in the equation:

$$
d_{i j}=\sqrt{\left(x_{i}-x_{j}\right)^{2}+\left(y_{i}-y_{j}\right)^{2}}
$$

Second, the savings value between customer $\mathrm{i}$ and $\mathrm{j}$ is calculated:

$$
s_{i, j}=d_{1, i}+d_{j, 1}-d_{i, j}
$$

Third, all savings values are sorted in the decreasing order. Beginning with the topmost entry in the list (the largest $s_{i, j}$ ). Finally, starting from the top of the savings list, $\mathrm{CW}$ includes link $(\mathrm{i}, \mathrm{j})$ in a route if no route constraints will be violated through the inclusion of customer $\mathrm{i}$ and $\mathrm{j}$ in that route(Caccetta, Alameen, \& Abdul-Niby, 2013).

\section{Results and Discussion}

In this study, hybrid algorithm, which is the sequential use of Clarke \& Wright's savings algorithm and genetic algorithm, is used for assignment of the truck and drone to serve the customer. The solution of the genetic algortihm is enhanced with Clarke \& Wright's savings algorithm and a new heuristic algorithm which aims to find the distances is used to connect the drones with truck to minimize the total delivery distance according to the assignment decisions. Experimental analyses were conducted to evaluate the performance of the proposed algorithm. It was conducted on the data set which is included the work of the Agatz et al. (2018). This instances with single center including from the coordinates $(\mathrm{x}, \mathrm{y})$ of customer and speed of drone and truck. It is aimed to calculate the same total delivery distances.

\subsection{Results of Genetic Algorithm}

In the solution process of GA, an initial population is randomly created depends on the number of customer. The roulette wheel selection method is used to perform the reproduction process which allows the genes to be transferred to the next generation. A single crossover method is applied to increase the diversity among individuals with cross-over rate $=80 \%$. After the crossover, the discrimination mutation process is carried out to change the genes that individuals have with the mutation rate $=30 \%$. The other genetic algorithm parameters are considered as follows iteration $=100$ and population size $=100$. The aim of using the genetic algorithm is determine the delivery type for the specified customers. The assignment continue until the number of the iteration is satisfied. In the Table 1, the delivery type is determined with genetic algortihm. 


\subsection{Results of Clarke and Wright's Saving Algorithm}

Clarke and Wright's Savings Algorithm is used to sequence of the customers(route) and another heuristic which aims to find the minimum distance is used to connect the drone to trucks(delivery type). Determined route in Table 1 is arranged with the Clarke and saving algortihm and connection of the drone and truck is made with new heuristic algorithm which is developed in this study. The aim of this new heuristic optimization is to define the drone and truck combination where they are closer to each other because truck waits the drone until the drone turn back to the same node where it launched. The route and the connection of the truck and drone is illustarated in Table 1. Determination of the route and the delivery type is applied the ten different instances as shown in the Table 1. Customer number (n) is taken as a 9 in all ten problem sets because the node in 0 indicate the depot where the truck and drone begin and end their delivery. In delivery type at the Table 1, "1" is used to show the truck assignment and "2" is used to show the drone assignment of the customer who is in the same sequence in the route. Distance in the Table 1, shows the minimum total delivery distances of the truck as long as all the customer orders are delivered.

Table 1: The Route and Delivery Type Assignment for Different Problem Sets

\begin{tabular}{|c|c|c|c|c|}
\hline & Iteration & Distance & Route & Delivery Type \\
\hline$n=9$, problem 1 & 100 & 376,68 & $0-2-6-7-4-5-1-8-9-3-0$ & $1,1,1,2,2,1,2,1,1$ \\
\hline$n=9$, problem 2 & 100 & 374,69 & $0-3-4-6-8-2-7-1-9-5-0$ & $1,2,1,1,1,2,1,2,1$ \\
\hline$n=9$, problem 3 & 100 & 435,36 & $0-5-3-7-4-8-2-1-9-6-0$ & $1,1,2,1,2,1,2,1,1$ \\
\hline$n=9$, problem 4 & 100 & 465,92 & $0-6-1-2-5-8-4-7-3-9-0$ & $1,2,2,1,1,1,2,1,2$ \\
\hline$n=9$, problem 5 & 100 & 381,56 & $0-1-6-4-8-2-7-3-5-9-0$ & $1,1,1,2,1,1,1,1,1$ \\
\hline$n=9$, problem 6 & 100 & 369,56 & $0-9-6-5-2-4-3-8-1-7-0$ & $1,2,1,2,1,1,1,2,2$ \\
\hline$n=9$, problem 7 & 100 & 333,65 & $0-1-5-8-4-7-3-2-6-9-0$ & $1,2,2,1,2,1,2,1,1$ \\
\hline$n=9$, problem 8 & 100 & 317,67 & $0-1-5-3-8-9-2-4-6-7-0$ & $1,2,1,1,2,1,1,1,1$ \\
\hline$n=9$, problem 9 & 100 & 461,24 & $0-9-3-4-5-7-2-8-1-6-0$ & $1,1,2,1,2,1,1,2,2$ \\
\hline$n=9$, problem 10 & 100 & 395,70 & $0-4-9-1-7-6-5-8-2-3-0$ & $1,2,1,2,1,1,1,1,1$ \\
\hline
\end{tabular}

To understand the outputs in Table 1, we illustrate problem 2 with $\mathrm{n}=9$ as a figure. In Figure 4, we clearly see where the delivery begins and end, where the truck and drone is connected and which customer deliveries satisfied with drone or truck. Node numbered with 0 indicates the depot where the deliveries begin and end. The nodes that determined as a square indicates the customers where the deliveries satisfied with truck and nodes with circle indicates the customers where the deliveries satisfied with drone. The delivery begins with the truck at node 0 and drone is in the truck at this node. While the truck deliver the order of customer at node 4 , the drone deliver the customer at node 3 and it turns back the same node (4). Truck waits the drone until the drone come back to the same node which resulted with the increasing the wating time of truck. This process continue until the all customer orders are satisfied.

\section{Conclusions and Recommendations}

In this study, hybrid algorithm, which is the sequential use of Clarke \& Wright's savings algorithm and genetic algorithm, is used for assignment of the truck and drone to serve the customer. The solution of the genetic algortihm is enhanced with Clarke \& Wright's savings algorithm and a new heuristic algorithm, which aims to find the distances, is used to connect the drones with truck to minimize the total delivery distance according to the assignment decisions. Experimental analyses were conducted to calculate the minimum total delivery distance of truck during the trip of truck and drone to serve the customers. This is the first hybrid approach in the literature including Clarke \& Wright's savings algorithm and genetic algorithm that applies for FSTSP problem. In this study, we assume that if the UAV is launched from $i$, it must return to the truck at node $i$. This condition is resulted with the increasing of the waiting time of truck which is the main drawback of this proposed hybrid algorithm. In future work we will make it optional. There is no comparison of the results with the previously studies in literature that used the same data sets. We will make a comparision with other studies in the literature, which use the same instances in the further study. 


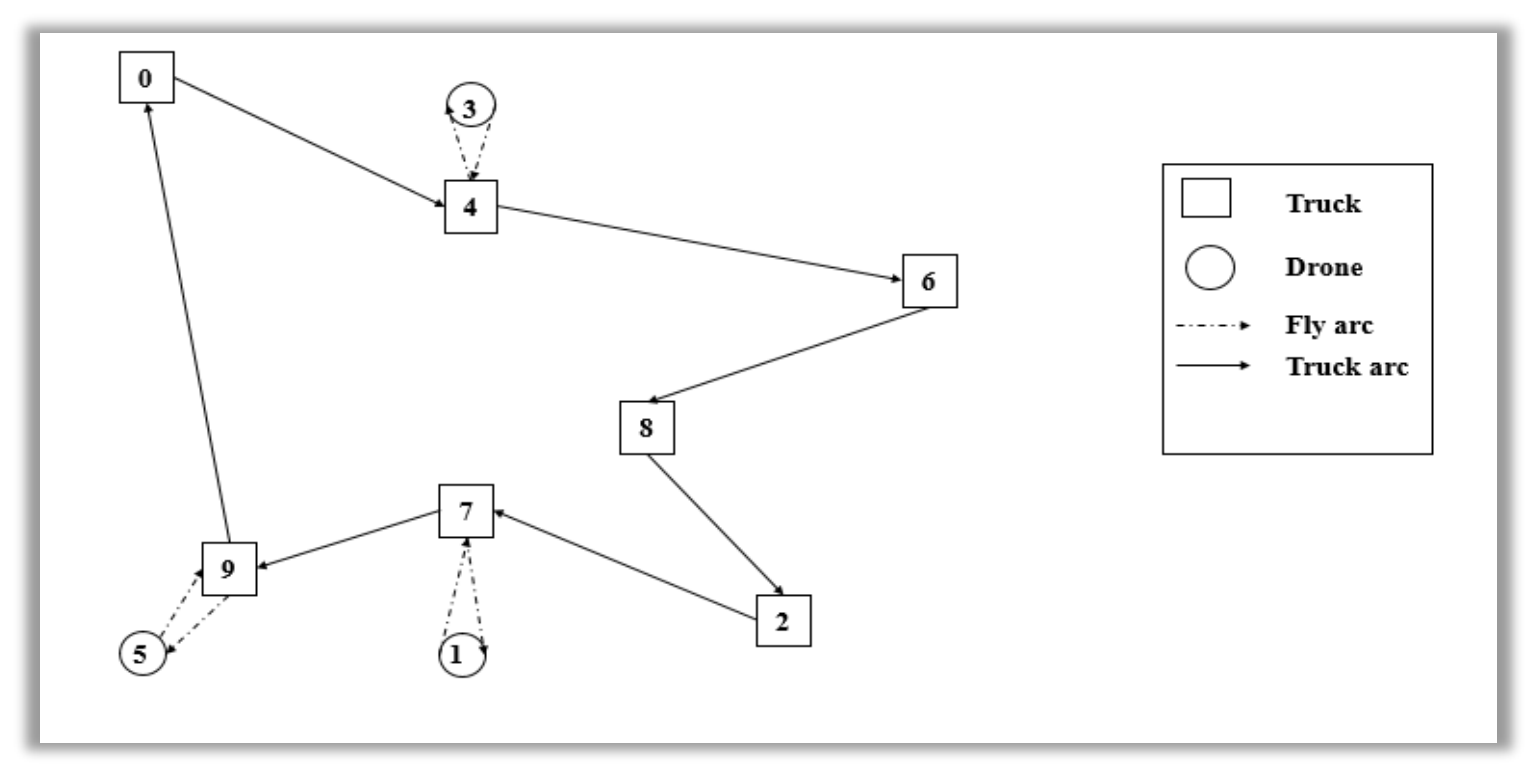

Figure 4: Illustration of the Problem Set 2 with $n=9$

\section{References}

[1]. Agatz, N., Bouman, P., \& Schmidt, M. (2018). Optimization Approaches for the Traveling Salesman Problem with Drone Optimization Approaches for the Traveling Salesman Problem with Drone. Transportation Science, 52(4), 965-981.

[2]. Baker, B. M., \& Ayechew, M. A. (2003). A genetic algorithm for the vehicle routing problem. Computers \& Operations Research, 30(5), 787-800. https://doi.org/10.1016/S0305-0548(02)00051-5

[3]. Bouman, P., Agatz, N., \& Schmidt, M. (2018). Dynamic programming approaches for the traveling salesman problem with drone, (October), 528-542. https://doi.org/10.1002/net.21864

[4]. Boysen, N., Briskorn, D., Fedtke, S., \& Schwerdfeger, S. (2018). Drone delivery from trucks: Drone scheduling for given truck routes. Networks, 72(4), 506-527. https://doi.org/10.1002/net.21847

[5]. Caccetta, L., Alameen, M., \& Abdul-Niby, M. (2013). An Improved Clarke and Wright Algorithm to Solve the Capacitated Vehicle Routing Problem. Technology \& Applied Science Research, 3(2), 413-415. https://doi.org/10.2306/scienceasia15131874.2012.38.307

[6]. Campbell, J. F., Sweeney, D., \& Zhang, J. (2017). Strategic Design for Delivery with Trucks and Drones. Supply Chain Analytics Report SCMA (04 2017).

[7]. Di, L., Pugliese, P., \& Guerriero, F. (2017). Last-Mile Deliveries by Using Drones and Classical Vehicles. In International Conference on Optimization and Decision Science (pp. 557-565). https://doi.org/10.1007/978-3-319-67308-0

[8]. Fan, S. S., Liang, Y., \& Zahara, E. (2006). A genetic algorithm and a particle swarm optimizer hybridized with Nelder-Mead simplex search. Computers \& Industrial Engineering, 50(4), 401-425. https://doi.org/10.1016/j.cie.2005.01.022

[9]. Ferrandez, Sergio Mourelo Harbison, T., Weber, T., Sturges, R., \& Rich, R. (2016). Optimization of a Truck-drone in Tandem Delivery Network Using K-means and Genetic Algorithm. Journal of Industrial Engineering and Management, 9(2), 374-388.

[10]. Ha, Q. M., Deville, Y., Pham, Q. D., \& Hà, M. H. (2018). On the min-cost Traveling Salesman Problem with Drone. Transportation Research Part C, 86(November 2017), 597-621. https://doi.org/10.1016/j.trc.2017.11.015

[11]. Huachi, P., \& Penna, V. (2018). A Randomized Variable Neighborhood Descent Heuristic to Solve the Flying Sidekick Traveling Salesman Problem, 66, 95-102. https://doi.org/10.1016/j.endm.2018.03.013

[12]. Jeong, H. Y., Lee, S., \& Song, B. D. (2019). Truck-Drone Hybrid Delivery Routing: Payload-Energy dependency and No-Fly Zones. International Journal of Production Economics, 214, 220-233. https://doi.org/10.1016/j.ijpe.2019.01.010

[13]. Kim, S., \& Moon, I. (2018). Traveling Salesman Problem With a Drone Station. In IEEE Transactions on Systems, Man, and Cybernetics: Systems (Vol. 49, pp. 42-52).

[14]. Kitjacharoenchai, P., Ventresca, M., Moshref-javadi, M., Lee, S., Tanchoco, J. M. A., Brunese, P. A., Engineering, I., Lafayette, W., \& States, U. (2019). Multiple traveling salesman problem with drones: Mathematical model and heuristic approach. Computers \& Industrial Engineering, 129, 14-30. https://doi.org/10.1016/j.cie.2019.01.020

[15]. Murray, C. C., \& Chu, A. G. (2015). The flying sidekick traveling salesman problem: Optimization of drone-assisted parcel delivery. TRANSPORTATION RESEARCH PART C, 54, 86-109. https://doi.org/10.1016/j.trc.2015.03.005

[16]. Pichpibul, T., \& Kawtummachai, R. (2012). New Enhancement for Clarke-Wright Savings Algorithm to Optimize the Capacitated Vehicle Routing Problem. European Journal of Scientific Research, 78(1), 119-134. Retrieved from https://www.researchgate.net/publication/267406368\%0Ahttp://www.europeanjournalofscientificresearch.com

[17]. Razali, N. M., \& Geraghty, J. (2014). Genetic Algorithm Performance with Different Selection Strategies in Solving TSP. Proceedings of the World Congress on Engineering, 2(1), 1-6.

[18]. Saleu, R. G. M., Grangeon, N., Deroussi, L., Feillet, D., \& Quilliot, A. (2018). An iterative two-step heuristic for the parallel drone 
scheduling traveling salesman problem. Networks, 72(4), 1-16. https://doi.org/10.1002/net.21846

[19]. Yoon, J. J. (2018). The Traveling Salesman Problem with Multiple Drones: An Optimization Model for Last-Mile Delivery. (Doctoral Dissertation, Massachusetts Institute of Technology).

[20]. Yurek, E. E., \& Ozmutlu, H. C. (2018). A decomposition-based iterative optimization algorithm for traveling salesman problem with drone $\square$. Transportation Research Part C, 91(July 2017), 249-262. https://doi.org/10.1016/j.trc.2018.04.009 